NBER WORKING PAPER SERIES

\title{
UNDERSTANDING INTERNATIONAL PORTFOLIO DIVERSIFICATION AND TURNOVER RATES
}

\author{
Amir A. Amadi \\ Paul R. Bergin \\ Working Paper 12473 \\ http://www.nber.org/papers/w12473 \\ NATIONAL BUREAU OF ECONOMIC RESEARCH \\ 1050 Massachusetts Avenue \\ Cambridge, MA 02138 \\ August 2006
}

The views expressed herein are those of the author(s) and do not necessarily reflect the views of the National Bureau of Economic Research.

C2006 by Amir A. Amadi and Paul R. Bergin. All rights reserved. Short sections of text, not to exceed two paragraphs, may be quoted without explicit permission provided that full credit, including $\odot$ notice, is given to the source. 
Understanding International Portfolio Diversification and Turnover Rates

Amir A. Amadi and Paul R. Bergin

NBER Working Paper No. 12473

August 2006

JEL No. F36

\begin{abstract}
This paper argues that fixed trading costs in international asset markets help explain equity home bias. This contrasts with explanations prevalent in international macroeconomics, which tend to be based on trading frictions instead in international goods markets, such as nontraded goods or transportation costs. While the stylized fact of high trading turnover in foreign holdings has been interpreted as evidence against international asset trading costs, we show that this argument only applies to costs that are proportional to trade, and not to fixed costs of entering the foreign market. After documenting that the home bias and turnover stylized facts remain valid in recent data, the paper constructs a very simple portfolio allocation model with various configurations of trading costs and with heterogeneous types of traders. A configuration with per unit costs heterogeneous among agents and a homogeneous fixed cost is found to replicate the pair of stylized facts. Intuitively, the lower trading costs that characterize larger and more efficient traders have two implications: firstly, these traders find it more profitable to enter foreign markets; secondly, their lower trading costs encourage a higher rate of trading turnover. Since holdings of international equities are disproportionately dominated by this class of larger and more efficient traders, average trading turnover is higher among international holdings.
\end{abstract}

Amir A. Amadi

Department of Economics

UC, Davis

One Shields Ave.

Davis, CA 95616

aaamadi@ucdavis.edu

Paul Bergin

Department of Economics

UC, Davis

One Shields Ave.

Davis, CA 95616

and NBER

prbergin@ucdavis.edu 


\section{Introduction}

Data on international equity markets suggest a pair of stylized facts that have proved difficult to reconcile. One is home bias: despite the potentially significant gains from foreign diversification, investors hold a disproportionately small amount of foreign equity. ${ }^{1}$ A second observation is that the turnover rate, the share of holdings bought or resold in a period of time, surprisingly is higher for assets held in a foreign market than for domestic assets.

One intuitively appealing explanation for home bias raised initially in the literature is the presence of international transactions costs associated with purchasing an asset in a foreign market. But if transactions costs were the explanation for small foreign holdings, it should also lower turnover among foreign assets. Since the opposite appears to be true, the literature moved on to other types of explanations. Research within the open economy macroeconomics literature has focused on transactions costs in the international goods market, which limit the ability to reap the benefits of asset diversification. ${ }^{2}$ Research within the finance literature has focused on information asymmetry between countries. ${ }^{3}$

However, while high foreign turnover might argue against trading costs of the usual proportional type, it does not rule out the presence of costs of a fixed type, that is, costs that are not proportional to the volume of trading. Recent research in the field of international trade theory has found that fixed costs of entry can be very useful in understanding aspects of international trade in goods markets. ${ }^{4}$ This paper studies theoretically if such fixed costs

\footnotetext{
${ }^{1}$ See French and Poterba (1991) and Tesar and Werner (1995).

${ }^{2}$ See Tesar (1993) and Pesenti and van Wincoop (2002) for examples of nontraded goods arguments. See van Wincoop (1994) and Aizenman (1999) for preferences. See Obstfeld and Rogoff (2001) and Engel and Matsumoto (2004) for various types of goods market imperfections. Rowland and Tesar (2004) investigate the role of multinational firms as a substitute for portfolio diversification.

${ }^{3}$ See Ahearne, Griever, and Warnock (2004) for example.

${ }^{4}$ See Bernard and Jensen (2004) for example.
} 
can be useful in understanding the puzzling aspects of international trade in equities markets, and what characteristics these costs would need to possess.

Interpretations of these fixed costs could include various types of establishment costs, like the need to deal with foreign languages and legal codes, or the costs of accessing information on a foreign firm. Amadi (2004a) finds empirical support for the idea that common language, distance and immigrant populations affect foreign investment.

In the context of a very simple portfolio allocation model, we find that a particular combination of fixed and proportional costs is able to generate the combination of stylized facts. The model includes proportional trading costs that are not heterogeneous between foreign and domestic assets, like those dismissed above, but instead are heterogeneous among agents within a country. Some agents have a cost advantage in executing financial trades, be it due to larger size, better technology, or expertise. In combination with uniform fixed costs of entering a foreign market, only efficient agents with low per unit costs find it profitable to enter. Therefore high cost agents remain solely in the domestic market, thereby resulting in a home bias. In addition, the agents with lower costs of trading naturally adjust their portfolio more often, resulting in a higher turnover rate. And since these agents are the only home-country agents active in the foreign market, this results in a relatively higher turnover rate in foreign investments.

The paper also presents basic empirical work, arguing that despite recent increases in international diversification and despite measurement issues raised in Warnock (2002), the stylized facts are still broadly relevant in recent data. We also compare our explanation for the puzzle to that in Rowland (1999), which notes that the volume of trade between home and foreign equities is high when agents are in the initial stages of diversifying. 
The next section examines recently improved international data on turnover to show that the basic stylized facts still are broadly relevant. Section 3 presents the portfolio allocation model, and section 4 shows how it can generate results similar to the stylized facts. Section 5 explores the model's sensitivity to alternative parameter values and compares the model to alternative configurations of the trading costs. The final section summarizes results and draws implications for other related questions regarding international equity markets.

\section{What recent data have to say}

Results in Tables 1 and 2 verify that the puzzling stylized facts motivating our model are generally valid in current data. While the main focus is on turnover rates, we document first that there still is substantial home bias in equity holdings, as shown in Amadi (2004b). The first column of Table 1 reports the share of country portfolios in foreign equities by country and by date. The data on foreign equity positions are obtained from the International Monetary Fund's IFS database, compiled using both survey and capital flow data. Likewise, the first column of Table 2 reports the same variable but using equity holdings data from the IMF's coordinated portfolio investment survey, which uses purely survey data (see the data appendix for a more detailed discussion of the data sources). While one notes an interesting upward trend in the degree of diversification, it remains quite small for most countries, and certainly it is smaller than the share implied by simple optimal portfolio models. The trend of rising diversification has also been noted in Amadi (2004b), Heathcote and Perri (2004), and Lane and Milesi-Ferretti (2003).

The empirical literature defines the foreign turnover rate as the total foreign 
transactions that occur within a given year divided by the foreign asset position at the end of the year. The domestic turnover rate is defined as the total domestic market transactions in a year divided by the year-end domestic market's capitalization. ${ }^{5}$ Tesar and Werner (1995) drew attention to the gap between home and foreign turnover rates for their data from 1989, finding a foreign turnover of 7.7 for Canada compared to a domestic turnover of only 0.61 , and a foreign turnover of 2.5 for the U.S. compared to 1.07 for domestic.

Table 1 shows updated turnover rates for Canada, Germany, Japan, and the United States for the last decade. The foreign turnover rates appear to be generally lower than those reported by Tesar and Werner, but nonetheless, they are almost uniformly higher than the corresponding domestic turnover rate. The only possible exception is for some recent years in the U.S., depending on whether Nasdaq values are included along with NYSE. Nasdaq reports notably higher turnover, though this may largely reflect a different convention for reporting turnover in this market. ${ }^{6}$

Warnock (2002) has correctly criticized Tesar and Werner's estimates for using data on foreign stock holdings that rely upon cumulated capital flows and estimated valuation adjustments. He finds that this leads to an underestimation of the holdings used in the denominator of the foreign turnover ratio, so the ratio itself is overestimated. To correct for this problem, he recommends using survey data. Such data have been available for the United States since 1989, and he constructs an estimate for Canada to use in comparisons with Tesar and Werner.

\footnotetext{
${ }^{5}$ The theoretical literature generally takes the values for the denominator from the midpoint of the year, rather than the end of the year. It is mainly due to the fact that asset position data are sometimes unavailable on a consistent annual basis that the empirical literature uses end of year values. The two definitions seem to produce similar results.

${ }^{6}$ Standard and Poor's 2003 Global Stock Markets Factbook notes that Nasdaq values include both sides of transactions when reporting 'value traded,' used in computing turnover (page 29).
} 
Following Warnock, Table 2 computes turnover rates ${ }^{7}$ using data from the IMF's Coordinated Portfolio Investment Survey, which relies on survey data. The results are essentially the same as those in Warnock for 1997 (the year of survey data available to him). ${ }^{8}$ We also report values for subsequent years of the surveys, which at times vary from the 1997 values substantially. Although the surveys are available for only a few years, we can compare the common entries for Tables 1 and 2. For the U.S. and Japan, the turnover rates are unaffected, for Canada the adjusted ratios are indeed lower, but for Germany the adjusted ratio is higher. Overall, the ratios are very close to those reported in the larger data set of Table 1. Most importantly, the foreign turnover rates remain higher than their domestic counterparts in almost every case.

We conclude that the foreign turnover rates are generally lower than those reported in the initial empirical literature, but the puzzling stylized fact remains, in that there is a consistently positive gap between turnover rates in foreign compared to domestic equity holdings. This would seem to support the common wisdom that transaction costs cannot be important here as an explanation for home bias. After all, if buying foreign equities carried a higher cost than equities in one's own market, not only would one tend to accumulate a smaller stock of these foreign assets, but there likely would be a smaller flow of purchases. Clearly, this is not the case in the data.

Before turning to the theoretical model, it is worth noting that the turnover in foreign equities is greater than $100 \%$ of the stock of foreign equity holdings in almost all cases. Given that the growth in the stock of foreign holdings in Table 1 evolves fairly

\footnotetext{
${ }^{7}$ Here the empirical definition for turnover rates are used since this survey data is not available on an annual basis.

${ }^{8}$ The U.S. domestic turnover rate that we reported is a composite of the NYSE and Nasdaq. Warnock (2002) presents the NYSE and Nasdaq rates separately.
} 
slowly in some countries, it would seem that the turnover cannot solely be in the form of net sales of home for foreign equities, as implied by the theoretical model of Rowland (1999). Either domestic participants in the foreign market are selling foreign equities back and forth to each other or, more likely, domestic participants in the foreign market are also tending to adjust their portfolio of foreign assets, trading one foreign asset for another.

That is, we are seeing turnover within the foreign market as well as between home and foreign assets. This observation helps motivate the model below, which allows turnover within the foreign market between distinct foreign assets.

\section{A simple fixed cost portfolio allocation model}

This study uses a Markowitz (1952) mean-variance model augmented with transactions costs, similar to that presented in Wang (2002). This class of models characterizes the optimal portfolio choice of individual investors, given asset returns that follow an exogenous stochastic process. ${ }^{9}$ Our objective is to demonstrate that trading costs of a particular type can induce higher turnover in foreign markets among these agents, at the same time as inducing home bias in their equity holdings. Specifically the agent's utility function is expressed as:

$$
U(c)=E(c)-\frac{\lambda}{2} \operatorname{Var}(c)
$$

where: $\quad E(c)=W\left(\sum_{i=1}^{4} R_{i} x_{i}+R_{0} x_{0}-\tau_{i, k} \sum_{i=1}^{4}\left|x_{i}-x_{i, t-1}\right|\right)-F \cdot z$

\footnotetext{
${ }^{9}$ The model examines the behavior of a group of agents who share similar beliefs; in actuality the trade between agents in equilibrium presumably arises from heterogeneity in beliefs regarding expected returns. Thus this model does not attempt to provide a full equilibrium explanation for turnover in an entire market. However, the model's main mechanism applied here to a set of agents, can in principle be incorporated into an aggregate analysis of the entire market.
} 


$$
\operatorname{Var}(c)=W^{2}\left(\sum_{i=1}^{4} \sum_{j=1}^{4} x_{i} x_{j} \sigma_{i j}\right)
$$

$W$ represents the agent's wealth, and $c$ the agent's consumption. $R_{\mathrm{i}}$ represents the risky asset $i$ 's expected return, and $\lambda$ a coefficient describing risk aversion. In the model there are four risky assets $(i=1,2,3,4)$, the first two are in the local market, while the latter two are in the foreign market. Modeling four assets allows for trading both between the domestic and foreign markets, as well as within the foreign market itself. Here $x_{i}$ represents the share of the agent's wealth devoted to asset $i$ in the current period, while $x_{i, t-1}$ represents last period's share of wealth devoted to asset $i$. Similarly $x_{0}$ and $R_{o}$ represent the share of wealth invested in the riskless asset and its return.

Two key features of the model are the proportional transactions cost $\tau$ and the fixed foreign entry cost $F$. Specifically $\tau_{i, k}$ is the constant transaction cost associated with a perunit change in the share of asset $i$ by agent $k$. That is, it is associated with both the purchase and the sale of asset $i$. In this model, different agents incur inherently different trading costs. $F$ represents the fixed cost associated with entering the foreign market, and therefore $\mathrm{z}$ is a dummy variable, equal to unity if $\mathrm{x}_{3}>0$ or $\mathrm{x}_{4}>0$.

The agent maximizes his or her utility based on the following constraints:

$$
\sum_{i=1}^{4} x_{i}=1 \text { and } x_{i} \geq 0
$$

That is, asset shares must sum to agent's wealth, and short sales are not permitted.

Such barriers as language, institutional, and legal differences might prevent entry into a foreign market. Amadi (2004a) and Grinblatt and Keloharju (2001) have shown that investors typically invest in markets that possess the same language, culture, or some other 
form of familiarity. One way of modeling this familiarity barrier is through a fixed cost. That is, one can assume that there is a fixed cost of operating in a foreign market, which represents the cost involved in acquiring equivalent information about that market. Also Ahearne, Griever, and Warnock (2004), as well as Martin and Rey (2000), find that crosslisting significantly increases foreign diversification, which could be thought of as overcoming this fixed cost. Once again this concept is not entirely new to the theoretical literature. Portfolio allocation models like Merton (1987), involve investors that pay "setup" or "receiver" costs in order to acquire detailed information regarding a firm's earnings or signals, although the models are applied in a domestic context.

The motivation for having different transactions costs is quite intuitive. Typically institutional investors and large brokerage houses face lower transactions costs than do average individual investors. These larger entities trade in significantly higher volumes, have access to less costly trading mechanisms, and typically have trade agreements that make their transactions relatively inexpensive. For example, many mutual fund companies charge reduced fees or no fees to investors who purchase a certain level of shares, typically in the millions. Again, in general, some agents have a cost advantage in executing financial trades, be it due to better technology or expertise. It is reasonable, therefore, to assume that different agents face different per-unit transactions costs.

The domestic and the foreign turnover rates, respectively, are measured as:

$$
T O_{D}=\frac{\sum_{i=1}^{2}\left|x_{i}-x_{i, t-1}\right|}{\frac{1}{2} \sum_{i=1}^{2}\left(x_{i}+x_{i, t-1}\right)} \quad \text { and } \quad T O_{F}=\frac{\sum_{i=3}^{4}\left|x_{i}-x_{i, t-1}\right|}{\frac{1}{2} \sum_{i=3}^{4}\left(x_{i}+x_{i, t-1}\right)}
$$

Here the numerator represents the total changes in the asset shares, while the denominator represents the average position in the assets between the beginning and the end of the 
period. To avoid conflating equity trades between periods with capital gains during period $t-1$, turnover is computed as the difference between the allocation at the beginning of period $t$ and the allocation at the end of period $t-1$, after expected returns are realized.

Since it is difficult to draw analytical results from the first order conditions of the maximization problem above, we will rely upon simulations and comparative static analysis in the next section to demonstrate the model characteristics. Nonetheless the fundamental properties of the model are highly intuitive and are discussed here briefly. First, as $t$ (proportional transaction cost) increases, the amount of transactions decreases. Second, as $F$ (fixed foreign entry cost) increases, entry into the foreign market decreases. These results are obvious. Another implication is that as $t$ decreases more agents will enter the foreign market. This is because agents with lower proportional costs gain more by entering the foreign market than agents with higher proportional costs, so they will be more likely to pay the fixed cost to enter the foreign market. Furthermore, agents with lower proportional trading costs naturally trade more actively and have higher turnover rates. Since we concluded that it is these agents that tend to be present in the foreign market, we should expect to find that foreign holdings have a higher turnover rate than domestic holdings, which are averaged over agents with both high and low trading costs.

In order to better grasp these implications, several simplifying assumptions are made, and a comparative static analysis is presented. First it is assumed that agents have identical wealths normalized to unity. Second, with reference to the transactions costs, we only examine two types of agents, that of a "low cost" and a "high cost" agent. Furthermore these two types of agents carry the same weight and therefore are distributed evenly. However this could be extended to a model with a continuum of different types of 
agents with different weights. Finally it is also assumed that all risky assets have the same market weight. Therefore a fully diversified portfolio is one that would contain $50 \%$ foreign risky assets as a share of all risky assets. These simplifying assumptions help make the general implications of the model clearer.

This model is applied for two periods in a comparative static exercise in order to distinguish between the home bias and the turnover rate implications. In this analysis, returns are realized at the end of each period. In the first period agents enter the asset market and optimize their portfolio based on the market's characteristics and their own. One can imagine a case in which agents inherit wealth and would like to invest that wealth in the stock market, or a case in which agents would like to transfer money from their savings account into their investment account, and so this seems the most natural initial point for a model ${ }^{10}$. This period examines the extent to which agents diversify internationally. In the second period, the comparative static experiment considers the arrival of new information that shifts the expected returns of the assets. These agents thereby adjust their portfolios accordingly. This period examines the model's implications with respect to the domestic and foreign turnover rates.

\section{Deriving benchmark results}

A numerical simulation is useful to explore the implications of the model. We use a simple comparative static exercise. For simplicity assume that all risky asset returns are equal to 1.15 , the riskless asset return is equal to 1.05 , variances are equal to 0.2 , and correlation coefficients are equal to 0.25 . These numbers are within a reasonable range of

\footnotetext{
${ }^{10} \mathrm{X}_{\mathrm{i}, \mathrm{t}-1}=0$ in the first period.
} 
actual parameter values for the past decade ${ }^{11}$, and in the sensitivity analysis section a wider range of numbers are presented for comparison. Also the parameter describing risk aversion is set equal to 2 , which is common in the literature. As stated previously, the model only looks at two types of agents for simplicity; a low cost and a high cost agent. Suppose the low cost agent incurs a per-unit trading cost of 0.01 , while the high cost agent incurs a per-unit trading cost of 0.03 . These also represent reasonable values that are consistent with those used in other studies ${ }^{12}$.

Consider the first period problem optimizing over a cardinal utility function: agents will enter the foreign market only if the extra utility they receive from the foreign market investment is greater than the fixed cost of entry. So in order to assess their decision, one needs to compare the maximum possible utility each type of agent receives if they chose to enter the foreign market versus if they chose to remain solely in the domestic market.

We solve the optimization problem for the high cost agent conditional on the two possible choices for international investment. ${ }^{13}$ First, if the agent chooses to invest only in the domestic market, optimal portfolio shares at the end of period 1 are $\mathrm{x}_{\mathrm{i}}=0.15$ for the domestic risky assets $\mathrm{i}=1,2$, and $\mathrm{x}_{0}=0.70$ for the riskless asset, with resulting utility level $\mathrm{U}=1.060$. Alternatively if the agent enters the foreign market, optimal portfolio shares at the end of period 1 are $\mathrm{x}_{\mathrm{i}}=0.11$ for the two domestic and the two foreign assets $(\mathrm{i}=1,2,3,4)$ and $\mathrm{x}_{0}=0.56$ for the riskless asset, with resulting utility $\mathrm{U}=1.064$. Therefore if the foreign fixed cost of entry is less than 0.004 , the high cost agent in this example will optimally

\footnotetext{
${ }^{11}$ Specifically the values were chosen based on the annualized returns, rolled over monthly, from 19942004 of Citigroup, Ford, Deutsch Bank, and Volkswagen. These large cap stocks make an appropriate representation of two domestic and foreign assets.

${ }^{12}$ Rowland (1999) uses similar values to differentiate between the costs associated with trading in the domestic and foreign markets.

${ }^{13}$ All computations performed in this study were done using Mathematica's Multiplier Method Algorithm.
} 
choose to enter the foreign market. Note that for period 1 we report portfolio shares for the end of the period, after expected capital gains have been realized. ${ }^{14}$ This is to facilitate later computation of turnover rates as the trade in equities between periods, without conflating this with capital gains during period 1.

Solving similarly for the low cost agent, the solution for domestic investment is $\mathrm{X}_{\mathrm{i}}=0.19$ for both domestic assets 1 and 2, with utility $\mathrm{U}=1.066$. Entering the foreign market, the solution is $\mathrm{x}_{\mathrm{i}}=0.13$ for all four assets, with utility $\mathrm{U}=1.073$, and so if the foreign fixed cost of entry is less than 0.007 , the low cost agent will enter the foreign market.

Let us assume that the fixed cost of entry equals 0.005 , so that only low cost agents invest in the foreign market ${ }^{15}$. Recall that both types of agents are given the same market weight. This implies an overall average foreign diversification among equity holdings of $32 \%$, since the low cost agent is fully diversified, while the high cost agent remains solely in the domestic market and holds more of the riskless asset. These results are reported in Table 3, under the headings for model 1, period 1 . Together these agents produce a degree of diversification close to the empirical values we reported for some countries. These values can also be adjusted downward, if desired, by assigning weights to the two groups. In the second period, suppose that new information arrives that leads these agents to revise expected returns upward for one asset in each country and downward for the other asset in each country. In particular, suppose that the returns on assets 1 and 3 increase to

\footnotetext{
${ }^{14}$ The corresponding beginning-of-period equity shares for period 1 for the high cost agent are as follows: $\mathrm{x}_{1}=\mathrm{x}_{2}=0.14$ with $\mathrm{x}_{0}=0.72$ for the purely domestic portfolio. To derive the end-of-period portfolio shares reported in the text and Table 3, beginning-of-period allocations are multiplied by the expected rates of return ( 1.15 for the equities and 1.05 for the riskless asset), and the values divided by the new value of the overall portfolio, so that shares again sum to unity. These end-of-period shares are more appropriate for comparison with beginning-of-period shares from period 2 , as a measure of turnover. The change in portfolio shares between periods then represents the reallocation of shares in a portfolio with the same aggregate value, without conflating the sale of assets between periods with capital gains during period 1 . ${ }^{15}$ Although this difference in the utility gains between the two agents might seem small, if this example is extended into a more realistic multiple periods, this difference would become relatively more significant.
} 
1.2, while the returns of assets 2 and 4 decrease to 1.1 . This symmetric experiment is intended to represent the type of information received that might affect agents' expectations. Solving the optimization problem for this period, the portfolios are reallocated toward the higher-paying assets, and the resulting values at the beginning of period 2 are reported in Table 3, as model 1 and period 2. The agent that is able to execute trades at a lower cost naturally reallocates his portfolio more actively, both in the domestic and foreign markets. These reallocations allow us to compute a turnover rate for these agents with respect to the domestic and foreign markets: ${ }^{16}$

$$
\begin{aligned}
& T O_{D}=\frac{|0.27-0.15|+|0.13-0.15|+|0.28-0.13|+|0.01-0.13|}{0.5((0.27+0.15)+(0.13+0.15)+(0.28+0.13)+(0.01+0.13))}=0.64{ }^{17} \\
& T O_{F}=\frac{|0.28-0.13|+|0.01-0.13|}{0.5((0.28+0.13)+(0.01+0.13))}=0.96
\end{aligned}
$$

As one can see, the turnover rate is indeed higher for the foreign investments. This example demonstrates that the model can produce results similar to the two stylized facts that have been observed in the existing literature. First, fixed costs pose a hurdle for participating in the foreign market, and this hurdle will be prohibitive to those investors who also face high proportional trading costs in general, but it will not be prohibitive to agents with low proportional trading costs. So one implication is the desired result of 'home-bias.' But the second implication becomes obvious when we combine this with the fact that these low-cost traders have higher turnover in response to new information. Given that the foreign assets are held by these agents, average turnover for foreign assets will be relatively high. Turnover for domestic assets, however, is averaged over the high cost

\footnotetext{
${ }^{16}$ Note that we follow the convention in the theoretical literature of using the midpoint of the asset holdings in the denominator of the turnover rate.

${ }^{17}$ Computations are based on numbers with higher precision than the two decimals reported in the paper.
} 
traders as well, and hence will be relatively low. Although this model is a highly simple example and cannot hope to explain all of the dynamics involved in portfolio allocation, it can provide a revealing and useful framework to help understand the key stylized facts.

\section{Alternative parameters and cost specifications}

This section checks sensitivity of results to alternative calibrations in the numerical simulation. Figure 1 shows that as the variance of risky asset returns increases from 0.1 to 0.3 , the two turnover rates fall together, as the agents hold a smaller portion of their portfolio in risky assets. Nonetheless, the foreign turnover rate remains higher. Figure 2 shows that as the coefficient of correlation rises from 0 to 0.5 , initially the turnover rates spread apart, only to stabilize at higher correlations. This arises from the fact that a greater correlation across countries reduces the benefits of international diversification. Eventually agents will only invest in those assets with greater returns, thereby causing the investment behavior in the two markets to converge. Figure 3 shows that varying the risk aversion parameter from 1 to 3 has only small effects on the turnover rates. The robustness suggests that our mechanism for explaining high turnover could apply to a wide array of countries.

Next consider several alternative cost specifications. Table 3 reports results, and shows why the particular configuration of costs in section 3 is needed to generate the desired results. The simplest alternative specifies proportional costs and fixed costs that are both homogenous across agents and markets. Here all agents are assumed to have a proportional trading cost equal to 0.01 . Labeled as model 2, Table 3 shows that this case fails to replicate either stylized fact: there is no home bias, and domestic turnover equals

foreign turnover. We conclude that the mere presence of fixed costs is not sufficient; some 
type of heterogeneity is needed.

The next alternative is to invert our benchmark case, with heterogeneity in fixed rather than proportional costs. All agents face a trading cost of 0.01 , but different agents face different fixed costs of participating in the foreign market, such that only one group finds it beneficial to diversify internationally. Labeled model 3 in Table 3, there indeed is home bias in asset holdings, as well as a higher turnover abroad. While the gap in turnover rates is small compared to that in the benchmark case and to that in much of the data, it is surprising that foreign turnover exceeds domestic turnover at all in this case. Recall that the reason the benchmark case achieves higher foreign turnover is that the home agents in the foreign market by construction have lower trading costs - it was these lower proportional costs that lead them to enter the foreign market. But since proportional trading costs are uniform for all agents in this alternative case, what induces the agents in the foreign market to trade more aggressively in this experiment?

The reasoning for this case is a bit subtle. Recall that the experiment here is a symmetric rise in the expected returns of asset 1 in the home market and asset 3 in the foreign market. These agents would like to maximize the overall expected return of the portfolio by reallocating away from asset 2 and towards asset 1 in the home market, and away from asset 4 and towards asset 3 in the foreign market (for the agents who have invested in the foreign market). The cost of this less balanced portfolio, of course, is a rise in the overall risk (variance) of the portfolio. This tradeoff limits the degree of reallocation by investors, but the tradeoff is less severe for the agent with a portfolio diversified internationally. This is because the extra dimension of diversification gives the internationally diversified agent a lower overall risk (variance), which in turn gives the 
agent a greater flexibility in having a more unbalanced portfolio within each national market. Therefore the international agent responds more to the shift in expected returns, resulting in a higher turnover. While interesting, we do not emphasize this configuration of costs as the most likely explanation for the turnover puzzle for several reasons. First, the magnitude of the turnover gap is small. Second, the result is not robust to alternative experiments with different shocks, as will be demonstrated shortly.

The last configuration of costs to consider posits no fixed cost at all, but just heterogeneous proportional trading costs among assets. In particular, suppose a trading cost of 0.01 for the domestic assets and a trading cost of 0.03 for the foreign. This case is considered, mainly because it formalizes the simple type of explanation considered and discarded in earlier research on home bias, such as Tesar and Werner (1995). Confirming earlier conjectures, model 4 of the table shows that such a configuration of costs can generate home bias, but it cannot replicate the turnover puzzle.

Some recent research on the issue of turnover has focused on a different type of experiment. Rather than a shift in expected returns of one home asset relative to another, it has considered a shift in expected returns of the foreign market relative to home. ${ }^{18}$ Table 4 repeats the cost-configuration cases in Table 3 for this new type of experiment. The rise in foreign returns in this experiment naturally leads to a significant rise in foreign diversification in the second period of each case as agents shift toward foreign assets.

First is the benchmark case. Table 4 shows that this case continues to reproduce the stylized fact that foreign turnover is higher than domestic turnover. Thus the benchmark theory is robust to the alternative experiment. Model 2 continues to fail to replicate the

\footnotetext{
${ }^{18}$ In particular, Rowland (1999) naturally considers a shock of this type, as his model limits the number of risky assets to one representative asset in each country.
} 
stylized facts, as was found for the previous experiment. More informative is the fact that model 3 also fails here. Although foreign turnover was higher than domestic for this case in Table 3, it is reversed here. We conclude that a heterogeneous fixed cost is not a very robust explanation for the puzzle.

Finally, model 4 again considers the case of higher proportional trading costs in the foreign market. This configuration is similar to that used in the theoretical model of Rowland (1999), and further, the experiment here of an asymmetric shock between regions is roughly patterned after his. Table 4 shows that this configuration still does not work to generate foreign turnover higher than domestic.

We think there is reason to prefer our mechanism as a general explanation. First, our explanation is consistent with the wide range in the degree of home bias among our sample countries, as it does not require turnover to be associated with the initial stages of diversification. In addition in Rowland's model, once the cost adjusted Sharpe ratio ${ }^{19}$ of the foreign market exceeds that of the domestic market, home bias disappears and the domestic turnover rate becomes greater than the foreign rate. While reasonable for the US market in the 1980s, if we examine the Japanese market in the 1990s, the cost-adjusted Sharpe ratio of the world market likely exceeded that of the Japanese market. ${ }^{20}$ However, as Tables 1 and 2 indicate, Japan still exhibits a substantial equity home bias, while maintaining higher foreign turnover rates.

\section{Conclusion}

The international economics literature continues to be puzzled by home bias in

\footnotetext{
${ }^{19}$ The mean market return, adjusted for its transactions cost, divided by its standard deviation.

${ }^{20}$ In his highest cost difference example, adjusting for the costs produces the necessary results.
} 
equity holdings, especially since turnover rates tend to be higher among foreign compared to domestic holdings. In contrast to the usual presumption in the literature, this study points to trading costs of a particular type in the asset market as a useful approach. It demonstrates this point in a portfolio choice model with heterogeneous per-unit transactions costs and a homogenous fixed foreign entry cost. First, using current data, it shows that the foreign turnover rates are still notably higher than the domestic rate. Second, through its model, this paper demonstrates that having agents that face inherently different trading costs produces a world in which there exists a notable home bias and higher foreign turnover rates. The fixed cost of entry presented in the model also compliments empirical evidence in the finance literature showing that the cross-listing of equity and factors such as a common language increase foreign diversification. While the model used to demonstrate these points is simple, we think it points out a useful direction for future research in international macro on this issue.

We conclude by noting another implication of our model. Recall from Tables 1 and 2 that there appears to be a trend over time of rising international diversification starting in the second half of the 1990s for many of the countries. Our model suggests that one explanation could be a fall in the fixed costs of participating in a foreign market. Such a fixed cost reduction might reflect harmonization of institutions across countries, increased access to information abroad, or the development of market institutions like mutual funds. We leave study of this question to future research.

\section{References}

Ahearne, A.G., Griever, W.L., Warnock, F.E., 2004. Information costs and home bias: an 
analysis of U.S. holdings of foreign equities. Journal of International Economics 62, 313-336.

Aizenman, J., 1999. International portfolio diversification with generalized expected utility preferences. Canadian Journal of Economics 32, 995-1008.

Amadi, A.A., 2004a. Does familiarity breed investment? an empirical analysis of foreign equity holdings. SSRN Working Papers Series. , 2004b. International portfolio diversification in a new global environment. U.C. Davis mimeo.

Bernard, A.B., Jensen, J.B., 2004. Why some firms export. The Review of Economics and Statistics 86, 561-569.

Engel, C., Matsumoto, A., 2004. Home bias in equities under new open economy macroeconomics. University of Wisconsin mimeo.

French, K., Poterba, J., 1991. Investor diversification and international equity markets. American Economic Review 81, 222-226.

Grinblatt, M., Keloharju, M., 2001. How distance, language, and culture influence stockholdings and trades. The Journal of Finance 56, 1053-1074.

Heathcote, J., Perri, F., 2004. Financial globalization and real regionalization. Journal of Economic Theory 119, 207-243.

Lane, P., Milesi-Ferretti, G.M., 2003. International financial integration. IMF Staff Papers $50,82-113$.

Markowitz, H., 1952. Portfolio selection. The Journal of Finance 7, 77-91.

Martin, P., Rey, H., 2000. Financial integration and asset returns. European Economic Review 44, 1327-1350. 
Merton, R.C., 1987. A simple model of capital market equilibrium with incomplete information. The Journal of Finance 42, 483-510.

Obstfeld, M., Rogoff, K., 2001. The six major puzzles in international macroeconomics: is there a common cause? In: Bernanke, B.S., Rogoff, K. (Eds.), 2000 NBER Macroeconomics Annual. MIT Press: Cambridge.

Pesenti, P., van Wincoop, E., 2002. Can nontradables generate substantial home bias? Journal of Money Credit and Banking 34, 25-50.

Rowland, P.F., 1999. Transaction costs and international portfolio diversification. Journal of International Economics 49, 145-170.

_ Tesar, L.L., 2004. Multinationals and the gains from international diversification. Review of Economic Dynamics 7, 789-826.

Standard and Poor's, 2003. Global Stock Markets Factbook. McGraw-Hill Companies: New York.

Tesar, L.L., 1993. International risk-sharing and nontraded goods. Journal of International Economics 35, 69-89.

, Werner, I.M., 1995. Home bias and high turnover. Journal of International Money and Finance 14, 467-492.

van Wincoop, E., 1994. Welfare gains from international risksharing. Journal of Monetary Economics 34, 175-200.

Wang, S., 2002. Portfolio Selection and Asset Pricing. Springer: New York, New York. Warnock, F.E., 2002. Home bias and high turnover reconsidered. Journal of International Money and Finance 21, 795-805. 


\section{Data appendix}

Foreign Equity Asset Holdings: One source is The International Monetary Fund's International Financial Statistics (IFS) database. This data is based on both survey and cumulated capital flows data. Valuations and estimation adjustments were made accordingly. The data for most nations runs 1993-2001. The second source is the International Monetary Fund's International Coordinated Portfolio Investment Survey. This survey was conducted in 1997, 2001, and 2002. It was performed after recommendations were put forth so that all participating countries provided accurate consistent data on asset holding.

Foreign Transactions: Foreign transactions include data on the sales and purchases of foreign equity. For the United States, the data comes from the Treasury Department's United States Transactions with Foreigners in Long-Term Securities. The Canadian data comes from Statistics Canada's International Transactions in Securities and Foreign Stocks. The data for Japan comes from The 2003 Tokyo Stock Exchange Fact Book Gross Capital Flow Data on Japanese Investment in Foreign Securities. The German data comes from Balance of Payments Statistical Supplement to the Monthly Report 3, Financial Transactions with Non-Residents.

Domestic Transactions and Market Capitalization: The Standard and Poor's Global Stock Markets Factbook. For the U.S. we report data both including and excluding transactions in the NASDAQ stock exchange, since the S\&P Factbook states that academic studies have shown that the NASDAQ computes "both sides of a trade." 
Table 1 : Turnover Rates Based On IFS Data

\begin{tabular}{|c|c|c|c|c|c|}
\hline \multirow{2}{*}{ Country } & Year & Foreign Diversification & \multicolumn{2}{|c|}{ Domestic Turnover } & $\begin{array}{c}\text { Foreign Turnover } \\
\text { Rate }\end{array}$ \\
\hline & 1993 & 11.46 & \multicolumn{2}{|c|}{0.44} & 2.10 \\
\hline & 1994 & 13.71 & \multicolumn{2}{|c|}{0.51} & 2.15 \\
\hline & 1995 & 13.45 & \multicolumn{2}{|c|}{0.50} & 2.43 \\
\hline & 1996 & 12.33 & \multicolumn{2}{|c|}{0.55} & 2.07 \\
\hline & 1997 & 11.64 & \multicolumn{2}{|c|}{0.52} & 3.08 \\
\hline & 1998 & 13.57 & \multicolumn{2}{|c|}{0.61} & 2.52 \\
\hline & 1999 & 12.06 & \multicolumn{2}{|c|}{0.44} & 3.36 \\
\hline & 2000 & 13.29 & \multicolumn{2}{|c|}{0.75} & 3.79 \\
\hline & 2001 & 16.01 & \multicolumn{2}{|c|}{0.66} & 3.28 \\
\hline \multirow[t]{9}{*}{ Germany } & 1993 & 23.75 & \multicolumn{2}{|c|}{0.65} & 1.61 \\
\hline & 1994 & 28.21 & \multirow{2}{*}{\multicolumn{2}{|c|}{0.98}} & 1.11 \\
\hline & 1995 & 26.24 & & & 0.99 \\
\hline & 1996 & 26.11 & \multicolumn{2}{|c|}{1.17} & 1.51 \\
\hline & 1997 & 27.44 & \multirow{2}{*}{\multicolumn{2}{|c|}{$\begin{array}{l}0.65 \\
070\end{array}$}} & 3.03 \\
\hline & 1998 & 31.55 & & & 3.15 \\
\hline & 1999 & 32.41 & \multicolumn{2}{|c|}{0.57} & 1.49 \\
\hline & 2000 & 37.22 & \multicolumn{2}{|c|}{0.84} & 2.44 \\
\hline & 2001 & 39.65 & \multicolumn{2}{|c|}{1.32} & 1.96 \\
\hline \multirow[t]{7}{*}{ Japan } & 1995 & 4.17 & \multicolumn{2}{|c|}{0.34} & 0.72 \\
\hline & 1996 & 5.29 & \multicolumn{2}{|c|}{0.41} & 0.98 \\
\hline & 1997 & 7.58 & \multicolumn{2}{|c|}{0.56} & 1.33 \\
\hline & 1998 & 8.72 & \multirow{2}{*}{\multicolumn{2}{|c|}{$\begin{array}{l}0.38 \\
0.41\end{array}$}} & 1.12 \\
\hline & 1999 & 7.14 & & & 1.11 \\
\hline & 2000 & 9.14 & \multicolumn{2}{|c|}{0.85} & 1.50 \\
\hline & 2001 & 10.81 & \multicolumn{2}{|c|}{0.81} & 1.22 \\
\hline United States & 1993 & 10.25 & 0.65 & & 1.51 \\
\hline & 1994 & 11.85 & 0.70 & & 1.31 \\
\hline & 1995 & 10.96 & 0.74 & & 0.95 \\
\hline & 1996 & 11.38 & 0.84 & $0.55^{\#}$ & 0.96 \\
\hline & 1997 & 10.44 & 0.90 & 0.60 & 1.29 \\
\hline & 1998 & 10.79 & 0.98 & 0.66 & 1.26 \\
\hline & 1999 & 11.89 & 1.12 & 0.66 & 1.15 \\
\hline & 2000 & 11.97 & 2.11 & 1.00 & 1.97 \\
\hline & 2001 & 11.30 & 2.10 & 0.92 & 1.82 \\
\hline
\end{tabular}

The foreign turnover rate is equal to the sum of the domestic country's purchases and sales of foreign equity within the year divided by the domestic country's foreign asset equity position at the end of the year. The domestic turnover rate is equal to the total transactions in the domestic market within the year divided by the domestic market's capitalization at the end of the year. Foreign diversification is equal to the foreign equity assets held by the country divided by the sum of its stock market capitalization and foreign equity assets adjusted for its foreign equity liabilities. "includes the NASDAQ, while "excludes the NASDAQ. Data on foreign transactions are from individual country sources. Data on foreign equity positions are from the International Monetary Fund's IFS database. Data on domestic transactions and capitalization are from the Standard and Poor's Global Stock Market Factbook. See data appendix for more detail. 
Table 2 : Turnover Rates Based On CPIS Data

\begin{tabular}{|c|c|c|c|c|c|}
\hline Country & Year & Foreign Diversification & Domes & urnover & $\begin{array}{c}\text { Foreign Turnover } \\
\text { Rate }\end{array}$ \\
\hline \multirow[t]{3}{*}{ Canada } & 1997 & 17.60 & & & 2.22 \\
\hline & 2001 & 25.21 & & & 2.12 \\
\hline & 2002 & 30.51 & & & 3.82 \\
\hline \multirow[t]{2}{*}{ Germany } & 2001 & 32.31 & & & 2.62 \\
\hline & 2002 & 39.61 & & & 2.38 \\
\hline \multirow[t]{3}{*}{ Japan } & 1997 & 7.44 & & & 1.33 \\
\hline & 2001 & 10.58 & & & 1.22 \\
\hline & 2002 & 10.41 & & & 1.32 \\
\hline \multirow[t]{3}{*}{ United States } & 1997 & 9.99 & $0.90^{*}$ & $0.60^{\#}$ & 1.29 \\
\hline & 2001 & 10.88 & 2.10 & 0.92 & 1.82 \\
\hline & 2002 & 11.37 & 2.30 & 201 & 1.95 \\
\hline
\end{tabular}

The foreign turnover rate is equal to the sum of the domestic country's purchases and sales of foreign equity within the year divided by the domestic country's foreign asset equity position at the end of the year. The domestic turnover rate is equal to the total transactions in the domestic market within the year divided by the domestic market's capitalization at the end of the year. Foreign diversification is equal to the foreign equity assets held by the country divided by the sum of its stock market capitalization and foreign equity assets adjusted for its foreign equity liabilities. "includes the NASDAQ, while \# excludes the NASDAQ. Data on foreign transactions are from individual country sources. Data on foreign equity positions are from the International Monetary Fund's Coordinated Portfolio Investment Survey. Data on domestic transactions and capitalization are from the Standard and Poor's Global Stock Market Factbook. See data appendix for more detail. 
Table 3: Simulation Results for Symmetric Experiment

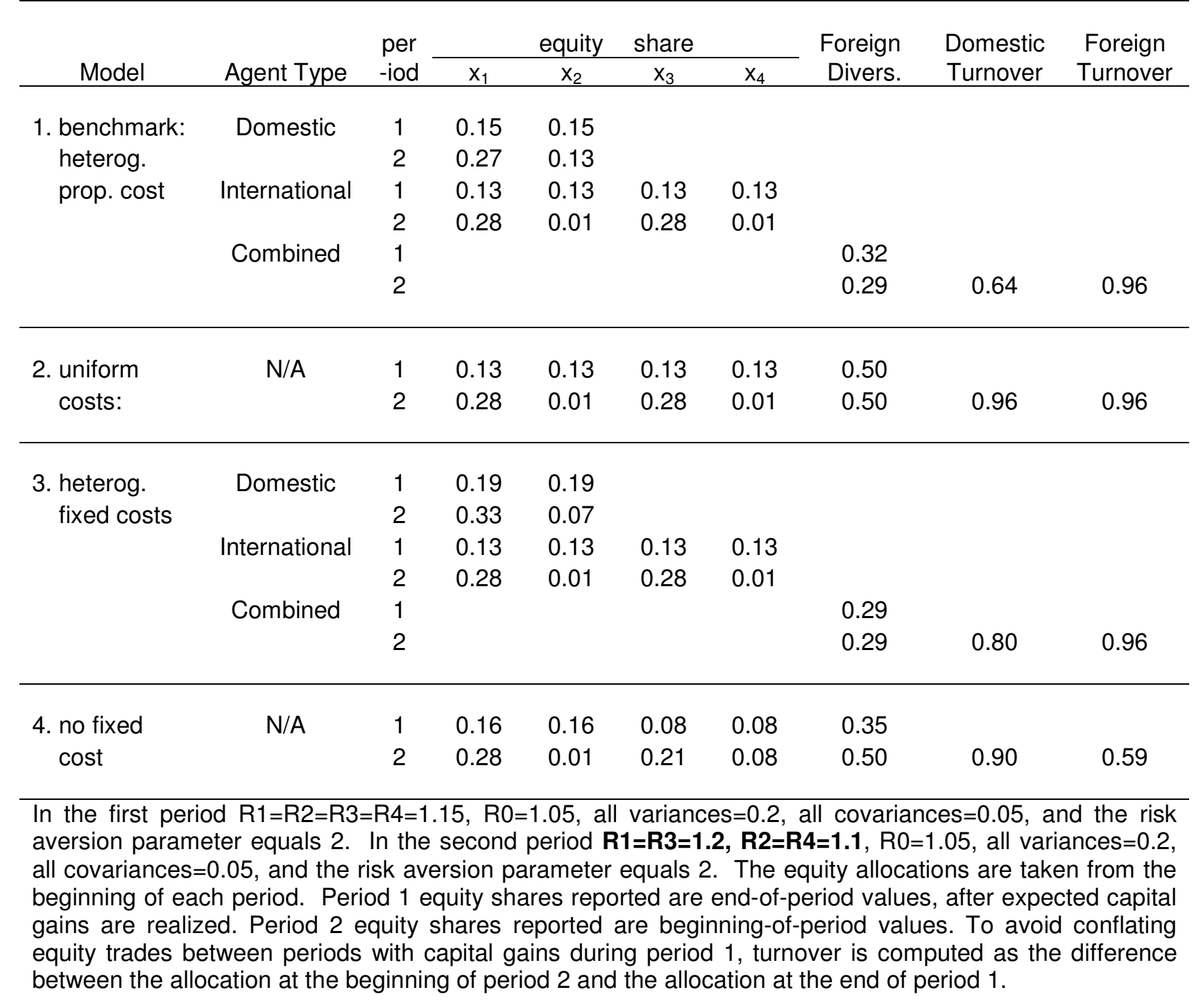


Table 4: Simulation Results for Alternative Experiment

\begin{tabular}{|c|c|c|c|c|c|c|c|c|c|}
\hline \multirow[b]{2}{*}{ Model } & \multirow[b]{2}{*}{ Agent Type } & \multirow{2}{*}{$\begin{array}{l}\text { per } \\
\text {-iod }\end{array}$} & \multicolumn{2}{|r|}{ asset } & \multicolumn{2}{|l|}{ share } & \multirow{2}{*}{$\begin{array}{l}\text { Foreign } \\
\text { Divers. }\end{array}$} & \multirow{2}{*}{$\begin{array}{l}\text { Domestic } \\
\text { Turnover }\end{array}$} & \multirow{2}{*}{$\begin{array}{l}\text { Foreign } \\
\text { Turnover }\end{array}$} \\
\hline & & & $x_{1}$ & $x_{2}$ & $x_{3}$ & $\mathrm{x}_{4}$ & & & \\
\hline \multirow{6}{*}{$\begin{array}{l}\text { 1. benchmark: } \\
\text { heterog. } \\
\text { prop. cost }\end{array}$} & Domestic & 1 & 0.15 & 0.15 & & & & & \\
\hline & & 2 & 0.14 & 0.14 & & & & & \\
\hline & International & 1 & 0.13 & 0.13 & 0.13 & 0.13 & & & \\
\hline & & 2 & 0.01 & 0.01 & 0.29 & 0.29 & & & \\
\hline & Combined & 1 & & & & & 0.32 & & \\
\hline & & 2 & & & & & 0.66 & 0.61 & 0.74 \\
\hline \multirow{2}{*}{$\begin{array}{l}\text { 2. uniform } \\
\text { costs: }\end{array}$} & $\mathrm{N} / \mathrm{A}$ & 1 & 0.13 & 0.13 & 0.13 & 0.13 & 0.50 & & \\
\hline & & 2 & 0.01 & 0.01 & 0.29 & 0.29 & 0.97 & 1.74 & 0.74 \\
\hline \multirow{6}{*}{$\begin{array}{l}\text { 3. heterog. } \\
\text { fixed costs }\end{array}$} & Domestic & 1 & 0.19 & 0.19 & & & & & \\
\hline & & 2 & 0.12 & 0.12 & & & & & \\
\hline & International & 1 & 0.13 & 0.13 & 0.13 & 0.13 & & & \\
\hline & & 2 & 0.01 & 0.01 & 0.29 & 0.29 & & & \\
\hline & Combined & 1 & & & & & 0.29 & & \\
\hline & & 2 & & & & & 0.59 & 0.86 & 0.74 \\
\hline \multirow{2}{*}{$\begin{array}{l}\text { 4. no fixed } \\
\text { cost }\end{array}$} & $\mathrm{N} / \mathrm{A}$ & 1 & 0.16 & 0.16 & 0.08 & 0.08 & 0.35 & & \\
\hline & & 2 & 0.03 & 0.03 & 0.23 & 0.23 & 0.89 & 1.38 & 0.93 \\
\hline \multicolumn{10}{|c|}{$\begin{array}{l}\text { In the first period } \mathrm{R} 1=\mathrm{R} 2=\mathrm{R} 3=\mathrm{R} 4=1.15, \mathrm{R} 0=1.05 \text {, all variances }=0.2 \text {, all covariances }=0.05 \text {, and the risk } \\
\text { aversion parameter equals } 2 \text {. In the second period } \mathrm{R} 1=\mathrm{R} 2=1.1, \mathrm{R} 3=\mathrm{R} 4=1.2, \mathrm{R} 0=1.05 \text {, all variances }=0.2 \text {, } \\
\text { all covariances }=0.05 \text {, and the risk aversion parameter equals } 2 \text {. Period } 1 \text { equity shares reported are end- } \\
\text { of-period values, after expected capital gains are realized. Period } 2 \text { equity shares reported are beginning- } \\
\text { of-period values. To avoid conflating equity trades between periods with capital gains during period } 1 \text {, } \\
\text { turnover is computed as the difference between the allocation at the beginning of period } 2 \text { and the } \\
\text { allocation at the end of period } 1 \text {. }\end{array}$} \\
\hline
\end{tabular}


Figure 1

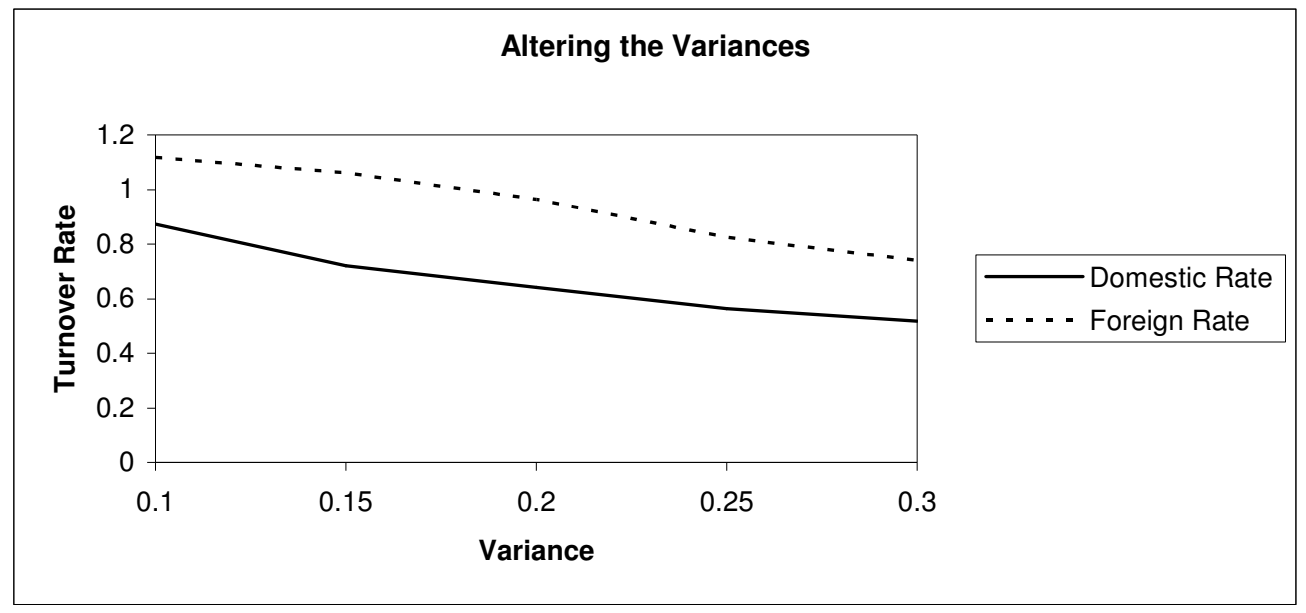

Figure 2

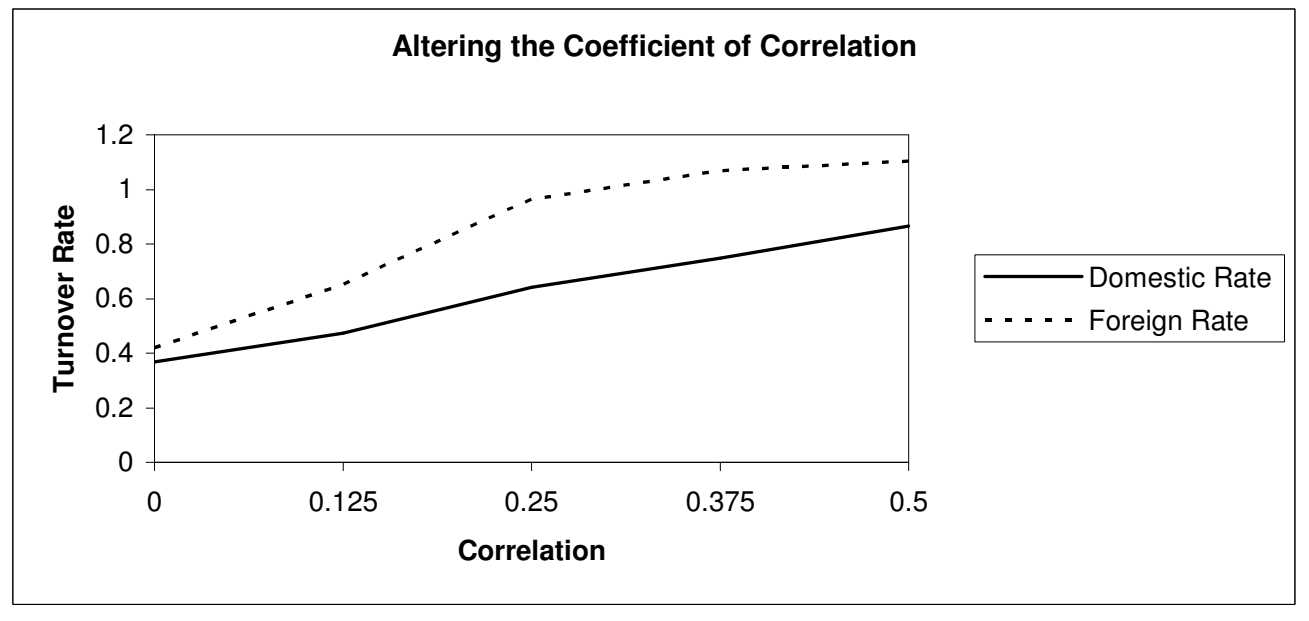

Figure 3

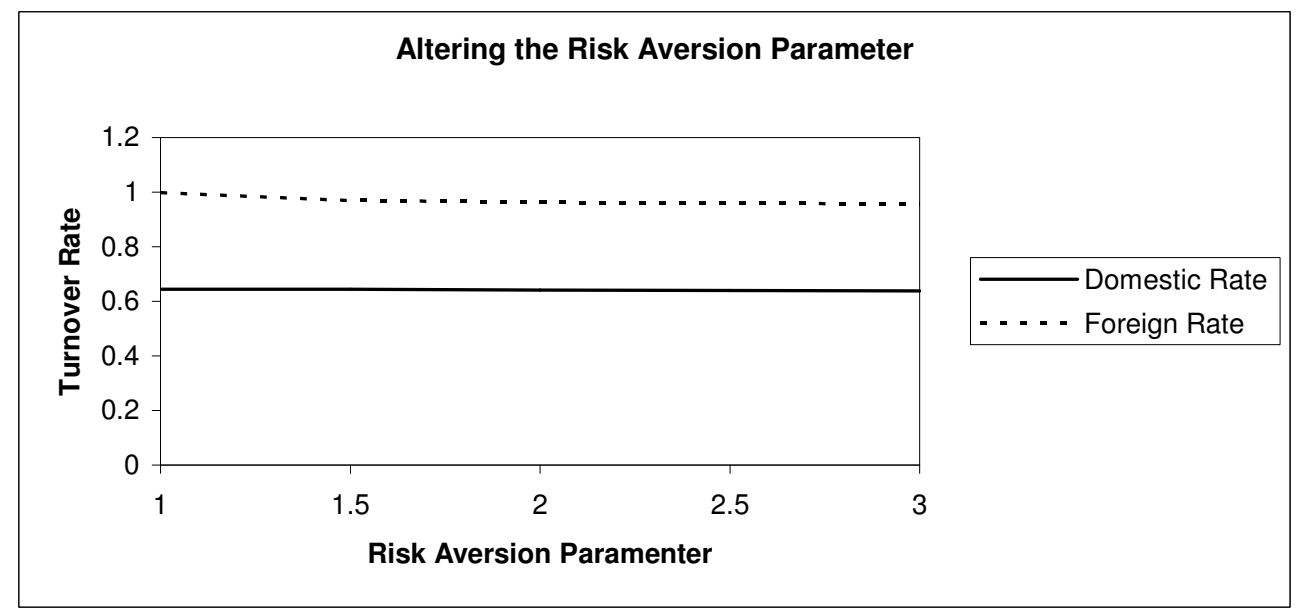

